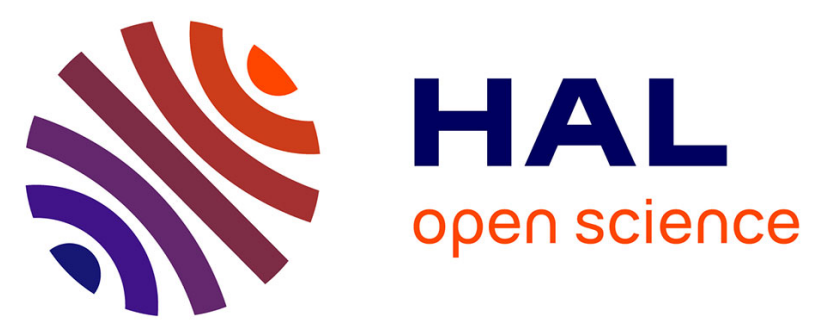

\title{
Study on the effect of grain storage and processing on chlorpyrifos-methyl and pirimiphos-methyl residues in post-harvest treated wheat with regard to baby food safety requirements
}

\author{
Anna Balinova, Rosica Mladenova, Doncho Obretenchev
}

\section{To cite this version:}

Anna Balinova, Rosica Mladenova, Doncho Obretenchev. Study on the effect of grain storage and processing on chlorpyrifos-methyl and pirimiphos-methyl residues in post-harvest treated wheat with regard to baby food safety requirements. Food Additives and Contaminants, 2006, 23 (04), pp.391-397. 10.1080/02652030500438035. hal-00577572

\author{
HAL Id: hal-00577572 \\ https://hal.science/hal-00577572
}

Submitted on 17 Mar 2011

HAL is a multi-disciplinary open access archive for the deposit and dissemination of scientific research documents, whether they are published or not. The documents may come from teaching and research institutions in France or abroad, or from public or private research centers.
L'archive ouverte pluridisciplinaire HAL, est destinée au dépôt et à la diffusion de documents scientifiques de niveau recherche, publiés ou non, émanant des établissements d'enseignement et de recherche français ou étrangers, des laboratoires publics ou privés. 


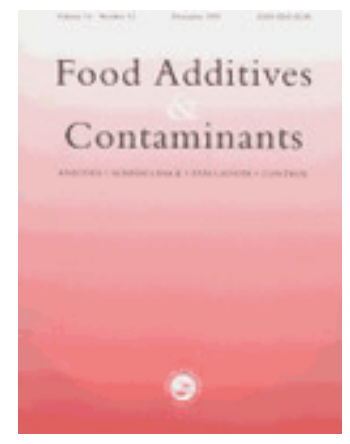

Study on the effect of grain storage and processing on chlorpyrifos-methyl and pirimiphos-methyl residues in postharvest treated wheat with regard to baby food safety requirements

\begin{tabular}{|r|l|}
\hline Journal: & Food Additives and Contaminants \\
\hline Manuscript ID: & TFAC-2005-113.R2 \\
\hline Manuscript Type: & Original Research Paper \\
\hline $\begin{array}{r}\text { Date Submitted by the } \\
\text { Author: }\end{array}$ & 23-Oct-2005 \\
\hline Complete List of Authors: & $\begin{array}{l}\text { Balinova, Anna; Plant Protection Institute, Toxicology } \\
\text { Mladenova, Rosica; Plant Protection Institute, Toxicology } \\
\text { Obretenchev, Doncho; Plant Protection Institute, Toxicology }\end{array}$ \\
\hline Methods/Techniques: & Chromatography - GC \\
\hline Additives/Contaminants: & Pesticide residues \\
\hline Food Types: & Baby food \\
\hline
\end{tabular}

\section{SCHOLARONE \\ Manuscripts}


Table 1. Recoveries and standard deviations of fortified pesticides from wheat versus matrixmatched standard calibration $(n=5)$

\begin{tabular}{|c|c|c|}
\hline Pesticide & Fortification level, mg.kg & Mean recovery $\pm \mathrm{SD}, \%$ \\
\hline Pirimiphos- & 0.005 & $106 \pm 4.2$ \\
methyl & 0.01 & $98.5 \pm 2.2$ \\
& 0.02 & $102 \pm 4.0$ \\
\hline Chlorpyriphos- & 0.005 & $122 \pm 12.5$ \\
methyl & 0.01 & $123 \pm 6.0$ \\
& 0.02 & $120 \pm 9.4$ \\
\hline
\end{tabular}


Table 2. Decline of chlorpyrifos-methyl residues in whole grain and processed products with time $(n=3)$

\begin{tabular}{|c|c|c|c|c|c|c|}
\hline \multirow{3}{*}{ Matrix } & \multicolumn{6}{|c|}{ Mean residue, $\mathrm{mg} \mathrm{kg}^{-1} \pm \mathrm{SD}$} \\
\hline & \multicolumn{6}{|c|}{ Days after treatment } \\
\hline & 0 & 7 & 30 & 90 & 180 & 270 \\
\hline Whole grain & $7.8 \pm 0.6$ & $5.4 \pm 0.4$ & $3.4 \pm 0.6$ & $3.0 \pm 0.2$ & $3.1 \pm 0.05$ & $3.3 \pm 0.04$ \\
\hline Bran & & $19.4 \pm 0.0$ & $10.1 \pm 0.03$ & $13.4 \pm 0.3$ & $13.6 \pm 0.0$ & $11.6 \pm 0.2$ \\
\hline Semolina & $\theta$ & $19.6 \pm 0.7$ & $8.0 \pm 0.02$ & $6.1 \pm 0.1$ & $6.80 \pm 0.6$ & $8.0 \pm 0.1$ \\
\hline Groats $1^{\text {st }}$ fraction & 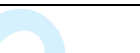 & $1.5 \pm 0.1$ & $1.0 \pm 0.02$ & $1.1 \pm 0.02$ & $1.01 \pm 0.06$ & $1.1 \pm 0.0$ \\
\hline Groats $2^{\mathrm{d}}$ fraction & 2 & $3.0 \pm 0.1$ & $1.3 \pm 0.1$ & $1.1 \pm 0.001$ & $1.3 \pm 0.06$ & $1.1 \pm 0.0$ \\
\hline Groats $3^{\mathrm{d}}$ fraction & & $4.7 \pm 0.4$ & $1.6 \pm 0.1$ & $1.4 \pm 0.001$ & $0.9 \pm 0.03$ & $1.3 \pm 0.03$ \\
\hline Flour $1^{\text {st }}$ fraction & & $3.7 \pm 0.3$ & $0.9 \pm 0.003$ & $0.7 \pm 0.03$ & $1.2 \pm 0.06$ & $0.8 \pm 0.01$ \\
\hline Flour $2^{\mathrm{d}}$ fraction & & $5.1 \pm 0.04$ & $0.6 \pm 0.03$ & $0.9 \pm 0.01$ & $1.1 \pm 0.0$ & $1.2 \pm 0.0$ \\
\hline Flour $3^{\mathrm{d}}$ fraction & & $4.7 \pm 0.4$ & $1.0 \pm 0.001$ & $1.4 \pm 0.01$ & $1.5 \pm 0.0$ & $2.1 \pm 0.1$ \\
\hline
\end{tabular}


Table 3. Decline of pirimiphos-methyl residues in whole grain and processed products with time $(\mathrm{n}=3)$

\begin{tabular}{|c|c|c|c|c|c|c|}
\hline \multirow{3}{*}{ Matrix } & \multicolumn{6}{|c|}{ Mean residue, $\mathrm{mg} \cdot \mathrm{kg}^{-1} \pm \mathrm{SD}$} \\
\hline & \multicolumn{6}{|c|}{ Days after treatment } \\
\hline & 0 & 7 & 30 & 90 & 180 & 270 \\
\hline Whole grain & $9.7 \pm 0.7$ & $6.8 \pm 0.6$ & $7.2 \pm 0.1$ & $6.9 \pm 0.3$ & $6.5 \pm 0.2$ & $5.2 \pm 0.1$ \\
\hline Bran & & $31.9 \pm 0.4$ & $24.4 \pm 3.3$ & $29.0 \pm 0.5$ & $10.4 \pm 0.1$ & $15.4 \pm 0.2$ \\
\hline Semolina & v & $21.7 \pm 1.0$ & $18.8 \pm 1.1$ & $21.6 \pm 0.4$ & $8.3 \pm 0.4$ & $13.9 \pm 0.5$ \\
\hline Groats $1^{\text {st }}$ fraction & 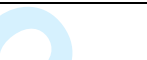 & $1.6 \pm 0.02$ & $2.5 \pm 0.2$ & $3.3 \pm 0.1$ & $2.8 \pm 0.1$ & $1.9 \pm 0.02$ \\
\hline Groats $2^{\mathrm{d}}$ fraction & 20 & $2.8 \pm 0.1$ & $3.1 \pm 0.2$ & $3.7 \pm 0.1$ & $3.5 \pm 0.2$ & $1.8 \pm 0.01$ \\
\hline Groats $3^{\mathrm{d}}$ fraction & & $4.8 \pm 0.2$ & $4.2 \pm 1.0$ & $3.7 \pm 0.1$ & $3.5 \pm 0.0$ & $2.2 \pm 0.04$ \\
\hline Flour $1^{\text {st }}$ fraction & & $3.7 \pm 0.1$ & $1.9 \pm 0.1$ & $2.8 \pm 0.1$ & $2.8 \pm 0.03$ & $0.6 \pm 0.01$ \\
\hline Flour $2^{\mathrm{d}}$ fraction & & $4.1 \pm 0.1$ & $2.6 \pm 0.1$ & $3.8 \pm 0.2$ & $1.5 \pm 0.3$ & $1.9 \pm 0.05$ \\
\hline Flour $3^{\mathrm{d}}$ fraction & & $5.9 \pm 0.2$ & $3.6 \pm 0.2$ & $3.9 \pm 0.1$ & $1.3 \pm 0.2$ & $3.7 \pm 0.1$ \\
\hline
\end{tabular}


Table 4. Residue balance of insecticides in processed products after 270 days of storage

\begin{tabular}{|c|c|c|c|c|}
\hline \multirow[t]{2}{*}{ Product } & \multicolumn{2}{|c|}{ Chlorpyrifos-methyl } & \multicolumn{2}{|c|}{ Pirimiphos-methyl } \\
\hline & Amount (mean),mg & $\%$ & Amount (mean),mg & $\%$ \\
\hline Bran & 5.0 & 50.5 & 6.8 & 43.6 \\
\hline Semolina & 2.7 & 27.3 & 5.2 & 33.4 \\
\hline Groats $1^{\text {st }}$ fraction & 0.1 & 1.0 & 0.2 & 1.3 \\
\hline Groats $2^{\mathrm{d}}$ fraction & 0.2 & 2.0 & 0.3 & 1.8 \\
\hline Groats $3^{\mathrm{d}}$ fraction & 0.1 & 1.0 & 0.2 & 1.2 \\
\hline Flour $1^{\text {st }}$ fraction & 1.0 & 10.1 & 0.07 & 0.4 \\
\hline Flour $2^{\mathrm{d}}$ fraction & 23 & 5.1 & 0.8 & 5.3 \\
\hline Flour $3^{\mathrm{d}}$ fraction & 0.2 & 2.0 & 0.3 & 2.1 \\
\hline Total & 9.8 & 99.0 & 13.9 & 89.1 \\
\hline Whole grain & 9.9 & 100 & 15.6 & 100 \\
\hline
\end{tabular}




\title{
Study on the effect of grain storage and processing on chlorpyrifos- methyl and pirimiphos-methyl residues in post-harvest treated wheat with regard to baby food safety requirements
}

\author{
A. Balinova, R. Mladenova and D. Obretenchev \\ Plant Protection Institute, Kostinbrod 2230, Bulgaria \\ E-mail: balinova@internet-bg.net
}

\section{Abstract}

A study was undertaken to assess the effects of storage intervals and of milling procedures on dissipation of chlorpyrifos-methyl and pirimiphos-methyl residues in post-harvest treated wheat grain with the aim to obtain scientific data on compliance of the processed products with the safety requirements concerning baby foods. The insecticide formulations were applied on stored wheat at recommended rates (20 $\left.\mathrm{ml} . \mathrm{t}^{-1}\right)$. The initial concentration levels in whole grain were determined in samples taken $1 \mathrm{~h}$ after treatment. The dissipation of residues and their distribution in different fractions of the milled grain were studied after various storage intervals, from 7 to 270 days after treatment. Samples of treated grain were milled in a fractionating laboratory mill and 8 fractions - bran, semolina, 3 types of groats and 3 types of flour were collected and analysed for pesticide residues. The residues were determined by an analytical method based on acetone extraction, graphitized carbon clean-up and GC-ECD, respectively GC-NPD determination of residues. The limits of determination of both pesticides were $0.005 \mathrm{mg} \cdot \mathrm{kg}^{-1}$ - high enough for enforcement of the European Commission (EC) Directive that established a maximum residue level ( $M R L)$ of 0.01 $\mathrm{mg} . \mathrm{kg}^{-1}$ for any pesticide in cereal-based baby food. 
The results showed that the pesticides chlorpyrifos-methyl and pirimiphos-methyl applied post-harvest on wheat as grain protectants were distinguished by relatively low rates of degradation in the grain under practical storage conditions. Milling did not significantly reduce the bulk of the chemicals but resulted in distribution of residues in various processed products. The main part of the insecticides deposited on the grain remained in the bran and partly in semolina fractions. 270 days after treatment the residues of chlorpyrifos-methyl were within the range of $0.8-2.1 \mathrm{mg}^{\mathrm{kg}}{ }^{-1}$ and of pirimiphos-methyl - between 0.6 and $3.7 \mathrm{mg} \mathrm{kg}^{-1}$ in the various types of flour.

Keywords: chlorpyrifos-methyl, pirimiphos-methyl, post-harvest treatment, wheat grain, processing products, residues, baby food

\section{Introduction}

Production of safe and healthy food is a key priority in EU and world-wide. Special attention has been paid to the health protection of infants and young children as they represent the most vulnerable group of population. Infants and young children have been shown to be very sensitive to certain toxic effects (Matsumura 2004, National Research Council 1993). Furthermore babies and young children are exposed to relatively higher doses of toxicants per body weight unit, compared to adults because of their proportionally higher consumption of food. Cereal-based products represent a substantive part of human's diet and particularly of baby's diet. Based on FDA data children receive 3 - 5 times more cereals than adults per body weight. For better protection of the health of infants and young children a general MRL of $0.01 \mathrm{mg} \cdot \mathrm{kg}^{-1}$ for any individual pesticide in processed cereal-based foods and baby foods has been established by EC (European Commission 2003a, b).

Post-harvest treatment for protection of raw grain against stored-product pests has been reported as a source of contamination of cereals (Joint Meeting on Pesticide Residues 1991, 1992). A summary of residue monitoring data sorted by frequency of incidents showed that grain protectants used on cereals accounted for most of the positive findings (Hamilton et al. 1997). The results of pesticide residues monitoring program of Portugal showed that wheat was found to contain frequently multiple residues, especially with those recommended as grain protectants - chlorpyrifosmethyl, pirimiphos-methyl and malathion (Pesticide residues monitoring in foodstuffs 
of vegetable origin, Portugal, 1999). Studies on the effect of storage on insecticide residues following post-harvest treatments have generally shown that residues decline rather slowly (Holland et al. 1994). Typically concentrations showed little decrease over 32 weeks at $20^{\circ} \mathrm{C}$ and $50-70 \%$ relative humidity. Chlorpyrifos-methyl and pirimiphos-methyl were reported more persistent than malathion (Holland et al. 1994). For refining of dietary intake estimates of pesticide residues a generation of food processing studies data has been required. Milling is one of the 10 processing methods identified as deserving main attention (World Health Organisation 1997). Studies on the fate of pesticide residues on grain subjected to milling and processing showed that the bulk of the insecticides deposited on the grain remained in the epidermis and was removed from the bran during milling. Most residues were found in the outer portion of grains (Hajslova 2000). The residues in bran have been reported to be consistently higher than in whole grain. The concentration on the bran was from 2 to 3.2 times the concentration on the whole wheat (Desmarchelier 1979a,b). Bran/grain concentration factors in the range of 2 to 6 were reported in many studies (Joint Meeting on Pesticide Residues 1988, 1989, 1991, 1992). Generally the amount of insecticide in flour was $10 \%$ or less of the concentration on the whole wheat. Yet the reduction of fenitrothion concentrations in flour was not found sufficient enough to comply with some MRLs particularly when wheat available had been treated within the previous two to three months at the recommended levels (Murray and Snelson 1978, Snelson 1979).

Chlorpyrifos-methyl and pirimiphos-methyl are registered as grain protectants and have been used as such for more than 30 years. The MRLs established for wheat grain intended for general nutritional uses are $3 \mathrm{mg} \cdot \mathrm{kg}^{-1}$ and $5 \mathrm{mg} \cdot \mathrm{kg}^{-1}$ respectively for both insecticides (European Commission 2002) The general MRLs are set on the basis of supervised trials in which Good Agricultural Practice is observed, on results, obtained under national and international monitoring programs etc. and must not pose an unacceptable risk to human health. These levels are subject to the requirements of international trade and as a rule are not violated.

The enforcement of the very stringent European Directive on residues in processed cereal-based baby food imposes the necessity of careful tuning of all technological parameters in order to select procedures that enable production of baby food in 
compliance with the established MRL from potentially contaminated raw materials. A study was thus undertaken aimed at assessment of the risk of baby food MRL violation due to utilisation of contaminated wheat grain for processing and production of baby food. It was focused on the influence of storage intervals and milling processes on behaviour of chlorpyrifos-methyl and pirimiphos-methyl applied on stored wheat grain.

The established MRL for residues in baby food is tens to hundreds times below the MRLs for food of general consumption. This imposes the necessity considerable attention to be paid to the problems of assurance the high quality of analytical methods both in respect of quantitative parameters (sensitivity, trueness, precision, and range) and of qualitative assessment (identification and confirmation). Implementation of analytical methods capable to determine the pesticides studied at or below $0.01 \mathrm{mg} \cdot \mathrm{kg}^{-1}$ was mandatory in the study.

The objectives of this work were: to study the influence of the wheat grain storage intervals and of milling on the decline and distribution of residues of the selected post-harvest applied insecticides in the processed fractions; to establish the residue balance of selected insecticides in processed products of post harvest treated wheat grain; to provide scientific data on compliance of the processed post-harvest treated wheat grain products with the safety requirements concerning baby foods.

\section{Materials and methods}

All processes applied to the study for processing effects assessment were planned in a way to correspond as closely as possible to those that occur in actual practices.

\section{Wheat treatment, sampling and processing.}

High grain quality wheat (Triticum estivum) cultivar "Momchil" was used in the experiments. The initial grain moisture was $14.0 \pm 0.5 \%$. The commercial insecticide formulations were Reldan 50 EC (chlorpyrifos-methyl $500 \mathrm{g.l}^{-1}$ active ingredient [a.i]) and Actellic 50 EC (pirimiphos-methyl $500 \mathrm{~g}^{-1}{ }^{-1}$ a.i). They were applied at recommended rate of $20 \mathrm{ml.t}^{-1}$, at working solution volume $1 \mathrm{l} .40 \mathrm{~kg}$ of wheat grain for each treatment were spread in about $1 \mathrm{~cm}$ thick layer and sprayed with $40 \mathrm{ml}$ of working solution. The application was accomplished by means of hand-operated 
spraying device. After treatment the wheat grain of each particular variant (and of untreated control) was mixed thoroughly and kept in open containers in a storehouse at conditions simulating the practical grain storage. The room temperature was $20 \pm 2^{\circ} \mathrm{C}$ and the air moisture $-70 \pm 5 \%$.

Samples of $0.5 \mathrm{~kg}$ grain of each variant were taken $1 \mathrm{hr}$ after treatment, when the grain became dry, for determination of the initial concentrations of pesticides in the whole grain. The following samplings were made after 7, 30, 90, 180 and 270 days storage periods. $3 \mathrm{~kg}$ of each treated grain variant and of untreated control were taken on particular sampling dates and submitted to milling in laboratory mill, simulating the industrial processing.

Milling was carried out in a fractionating laboratory mill Buhler MLU 202. Eight fractions: bran, semolina, groats (3 fractions), flour (3 fractions) were obtained and were submitted for analysis as well as whole grain.

\section{Chemicals}

Pesticide standards. Analytical standards of pirimiphos-methyl, purity $99.8 \%$ and chlorpyrifos-methyl, purity $99.9 \%$ were obtained from LGC Promochem (Wesel, Germany). Stock solutions ( $1.0 \mathrm{mg} \cdot \mathrm{ml}^{-1}$ ) of each pesticide were prepared in ethyl acetate and stored in a freezer at $-23^{\circ} \mathrm{C}$. Working standard solutions at concentration rates of $10 \mathrm{ng} \cdot \mathrm{ml}^{-1}-500 \mathrm{ng} \cdot \mathrm{ml}^{-1}$ were prepared by diluting of stock solutions with ethyl acetate and stored at $4^{\circ} \mathrm{C}$ in dark.

\section{Solvents and reagents.}

All organic solvents were of gas chromatography grade and were obtained from Merck KGaA (Darmstadt, Germany). Double distilled water was used when needed in experiments. Solid phase extraction (SPE) sorbent: graphitized carbon ENVI-Carb $120 / 400$ mesh, surface area $100 \mathrm{~m}^{2} / \mathrm{g}$, was obtained from Supelco (Bellefonte, PA, USA).

\section{Instrumentation.}

Hewlett-Packard gas chromatograph Model 5890 Series II equipped with ${ }^{63} \mathrm{Ni}$ electron capture detector (ECD) and nitrogen-phosphorus detector (NPD) was used. Split-splitless injector operated in the splitless mode. Capillary column ATTM-5ms, (30 
$\mathrm{m} \times 0.25 \mathrm{~mm} \times 0.25 \mu \mathrm{m})$ was obtained from Alltech Associates, Inc. (Lokeren, Belgium). Nitrogen of purity $99.9995 \%$ was used for gas chromatography. Vacuum manifold (Varian BV) was used for SPE.

\section{Analytical method}

Extraction. The weight of the analytical samples taken of different products varied depending on the expected levels of residue concentrations. The whole wheat grain laboratory samples were homogenised by mixing, analytical samples of $10 \mathrm{~g}$ were weight, $50 \mathrm{ml}$ mixed solvent acetone-water (8:2) were added and samples were extracted by shaking for 30 min on a shaking machine and left over night. Analytical samples of $10 \mathrm{~g}$ were weight of bran and semolina and extracted with $100 \mathrm{ml}$ of the solvent. $20 \mathrm{~g}$ analytical samples of flour and groats were extracted with $100 \mathrm{ml}$ of the solvent. The row extracts were filtered through filter paper and $25 \mathrm{ml}$ aliquot of each extract was taken for further SPE cleanup and pre-concentration.

\section{Sample clean up.}

$25 \mathrm{ml}$ of the acetone extracts were diluted with $200 \mathrm{ml}$ bidistilled water and the diluted extracts were submitted to SPE clean-up/preconcentration. SPE was carried out by using polypropylene cartridges manually packed with $400 \mathrm{mg}$ ENVI-Carb, conditioned with $10 \mathrm{ml}$ ethyl acetate:methanol (8:2) followed by $5 \mathrm{ml}$ methanol and washed with $10 \mathrm{ml}$ water. The sorbent was never allowed to dry up during the conditioning and sample loading steps. The samples were forced to pass through the sorbent under vacuum at rate of $10 \mathrm{ml} \mathrm{min}^{-1}$. After the passage of the sample, the cartridge was washed with $0.5 \mathrm{ml}$ of methanol and dried under vacuum for $30 \mathrm{~min}$. The pesticides

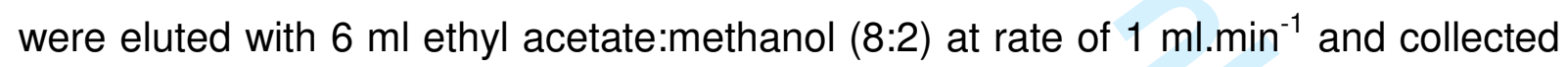
in $10 \mathrm{ml}$ graduated tubes. The final volumes of the samples were adjusted by dilution or evaporation under gentle nitrogen flow in order to obtain analyte concentrations appropriate to quantitative determination.

\section{Gas-Chromatographic determination.}

GC-NPD operating conditions: carrier gas nitrogen, at flow rate $2.5 \mathrm{ml} \mathrm{min}^{-1}$; make up nitrogen $30 \mathrm{ml} \mathrm{min}{ }^{-1}$; hydrogen $-4 \mathrm{ml} \mathrm{min}^{-1}$; air - $100 \mathrm{ml} \mathrm{min}^{-1}$; injector temperature $270^{\circ} \mathrm{C}$; detector temperature $300^{\circ} \mathrm{C}$. 
GC-ECD operating conditions: carrier gas nitrogen, at flow rate $2.5 \mathrm{ml} \mathrm{min}^{-1}$; make up nitrogen $30 \mathrm{ml} \mathrm{min}^{-1}$; injector temperature $270^{\circ} \mathrm{C}$; detector temperature $300^{\circ} \mathrm{C}$.

Oven temperature programme for both systems was: $100^{\circ} \mathrm{C}$, hold $1 \mathrm{~min}$; rate $20^{\circ} \mathrm{Cmin}^{-1}$ to $260^{\circ} \mathrm{C}$ final temperature, hold $3 \mathrm{~min}$.

Injection volume was $1 \mu \mathrm{l}$ for all samples. Quantification was performed by using external standards. Matrix-matched calibration standards were used for all quantifications.

The recovery studies were performed by using blank samples of untreated wheat grain. The weights of blanks were the same as the weights of the analytical samples of treated grains. The fortification was done by addition of calculated volumes of working standard solutions in order to obtain 3 concentration levels of the insecticides studied: at MRL $\left(0.01 \mathrm{mg} \cdot \mathrm{kg}^{-1}\right)$, below MRL $\left(0.005 \mathrm{mg} \cdot \mathrm{kg}^{-1}\right)$ and higher than $\mathrm{MRL}$ $\left(0.02 \mathrm{mg} . \mathrm{kg}^{-1}\right)$. Five parallel samples were prepared for each fortification level. After waiting time of $1 \mathrm{~h}$ for evaporation of the ethyl acetate from standard solutions the fortified samples were analysed according to the method described above.

\section{Results and discussion}

Single laboratory method validation:

The method was validated for the matrices studied.

The ECD response for chlorpyrifos-methyl was linear in the range of $0.005 \mathrm{ng}-0.05$ $\mathrm{ng}$ and the correlation coefficient $\mathrm{r}^{2}$ was higher than 0.98 (five-point calibration curve). The NPD response for pirimiphos-methyl was linear in the studied range of $0.01 \mathrm{ng}-$ $1.0 \mathrm{ng}$. The correlation coefficient $r^{2}$ for the five-point calibration curve was $>0.99$. Concentrations of the analytes in the samples were calculated by using single-level calibration method. This approach is recommended in case the detector response is variable with time (Document No SANCO/10476/2003). In our studies it was confirmed that single-level calibration gave more accurate results than multi-level calibration when the analytes concentrations in samples were adjusted in an interval $\pm 10 \%$ of the calibration level used. 
The mean recoveries and the repeatability expressed as standard deviation (SD), determined at three fortification levels (number of samples $n=5$ ) are presented in table 1.

The limits of quantification (LOQ) were adopted at $0.005 \mathrm{mg} \cdot \mathrm{kg}^{-1}$ for both analytes. The LOQ of the analytical method is strongly dependent not only on the response of the detector to the analyte but also on the matrix co-extractives in the final extract. It is possible to obtain higher sensitivity of the method for analytes of lower detector response if the sample extract does not contain interfering co-extractives. In case of pirimiphos-methyl the lowest calibrated level (LCL) was 0.01 microgram. $\mathrm{ml}^{-1}$. The clean extracts free of co-extractives made it possible to adjust the matrix concentration in the sample final solution to $2 \mathrm{~g} \cdot \mathrm{ml}^{-1}$ so the $L O Q$ was $0.005 \mathrm{mg} \cdot \mathrm{kg}^{-1}$. In

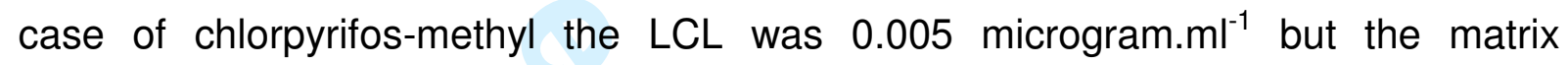
concentration in the sample final solution was only $1 \mathrm{~g} \cdot \mathrm{ml}^{-1}$ because some coextractives caused higher chromatographic noise. For that reason the LOQ for chlorpyrifos-methyl was also $0.005 \mathrm{mg} \cdot \mathrm{kg}^{-1}$, despite its higher absolute sensitivity compared to pirimiphos-methyl. The LOQ was specified for both pesticides at this concentration level because it ensured compliance with European Commission criteria for quantitative residue methods (Document No SANCO/10476/2003).

\section{Processing.}

The laboratory mill used for processing of the grain was a conventional device used for simulated fractionation that corresponds closely to the fractionation under the real industrial process. The results of residue analysis obtained from processing experiments carried out on stored wheat grain, treated post harvest with chlorpyrifosmethyl and pirimiphos-methyl are presented in tables 2 and 3.

Both insecticides were persistent under the conditions studied. After storage period of 270 days the average level of pirimiphos-methyl residues in the whole grain was 5.2 mg. $\mathrm{kg}^{-1}$ which was $53.6 \%$ of the concentration determined in the day of treatment. Under similar conditions chlorpyrifos-methyl was less persistent. The average residue level in grain after storage period of 270 days was $3.3 \mathrm{mg} \cdot \mathrm{kg}^{-1}-42.3 \%$ of the initial concentration determined in the day of treatment. These results show that the residues on grain following post-harvest treatments with insecticides decline rather 
slowly. This corresponds with the results of long residual effectiveness of postharvest applied insecticides on storage pests (Snelson 1987; Holland et al. 1994). Pirimiphos-methyl was reported as very stable in stored wheat with half-life at $30^{\circ} \mathrm{C}$ storage temperature 70 weeks. Chlorpyrifos-methyl under similar conditions was found to be less stable with half-life 19 weeks (Holland et al. 1994).

The distribution of chlorpyrifos-methyl and pirimiphos-methyl residues in fractions from processed wheat is presented in tables 2, 3 . The bulk of the insecticides deposited on the grain remain in the bran. The concentrations of chlorpyrifos-methyl in the bran are from 3.6 to 4.5 times as high as those present on the whole wheat grain. The residue levels of pirimiphos-methyl in the bran show a concentrating effect from 1.6 to 4.7 in comparison with the whole grain. Considerable part of the insecticides is distributed in the semolina fractions. The residues of chlorpyrifosmethyl and pirimiphos-methyl determined in semolina are only slightly lower the residues in bran and are respectively 2.0 -3.6 and 1.3 -3.2 times as high as those on the whole grain. Generally the residue levels of chlorpyrifos-methyl in flour are $1.6-$ 5.6 times lower of the concentration on the whole grain. The concentration interval of pirimiphos-methyl residues in flour is 2.1 - 3.4 times lower than the residues on the whole grain. The reduction of residues in flour and groats is mostly due to the removal of the insecticides with bran and partly with semolina fractions.

In order to determine the percentage loss of residues during processing the residual amounts in the separate fractions were calculated on basis of the weight of each fraction and the corresponding residue concentration. The balance of residues in all fractions compared to the amount on whole grain before milling, determined in samples taken after 270 days storage (Table 4), shows that the loss of chlorpyrifosmethyl during processing is less than $2 \%$ of the total amount on whole grain. Pirimiphos-methyl undergoes comparatively more substantial loss during milling - the loss of residues is determined to be about $10 \%$ (Table 4). Taking into consideration that volatilisation is one of the basic processes acting on pesticide residues this could be explained by the higher vapour pressure of pirimiphos-methyl- V.p.(40 $\left.{ }^{0} \mathrm{C}\right)=22 \mathrm{mPa}$ (Tomlin 2000) and the processes favourable to volatilisation - grinding, screening etc. 


\section{Conclusions}

The analytical method used was sensitive enough for reliable determination of chlorpyrifos-methyl and pirimiphos-methyl in wheat at concentration 0.01 mg. $\mathrm{kg}^{-1}$.

The storage time and milling of wheat grain, treated post-harvest against storedproduct pests with chlorpyrifos-methyl and pirimiphos-methyl at recommended application rates, are not effective enough to reduce the residues in grain and in milled products to levels at/below the general MRL of $0.01 \mathrm{mg} \cdot \mathrm{kg}^{-1}$ established by EC for any individual pesticide in processed cereal-based baby foods. The bulk of the insecticides deposited on the grain is removed with the bran and partly with the semolina fractions during milling but yet the reduction of residue concentrations in the flour and groats fractions is not sufficient for compliance with the baby foods safety requirements. All EC Directives concerning baby food safety stipulate that the exposure of infants and children to food contaminants is of particular concern because of their possible increased susceptibility for adverse effects. Growing and developing organisms have particular sensitivity to toxic compounds (Dencker and Ericsson 1998). The EC Directives on infant formulas and baby foods state that these products shall not contain any substance in such quantity as to endanger the health of infants and young children. The results of the work presented here indicate that the processed foods based on post-harvest treated wheat grain are not eligible for nutrition of infants and little children.

Taking into consideration the MRLs for foodstuffs of general consumption, the results of this study indicate that processed products (flour, groats) of wheat, treated postharvest with the insecticides studied, are in compliance with the safety requirements for general population.

\section{Acknowledgements}

The authors acknowledge the financial support of the NATO Program "Science for Peace" for Project № SfP 977983.

\section{References}

Dencker L, Ericsson P. 1998. Susceptibility in utero and upon neonatal exposure. Food Additives and Contaminants 15, 37-43 
Desmarchelier, J.M. 1979 ${ }^{a}$. The effect of milling and processing on the level and fate of grain protectant insecticide residues on wheat and oats. Report of CSIRO Division of Entomology, May, Canberra, Australia

Desmarchelier, J.M. $1979^{\mathrm{b}}$. Transfer of grain protectant insecticide residues from grain to wheat gluten. Report of CSIRO Division of Entomology, June, Canberra, Australia

European Commission 2000. Monitoring for Pesticide Residues in Products of Plant origin in the European Union, Norway, Iceland and Lichtenstein. Report 2000, Annex to SANCO $687 / 02 /$ final

European Commission 2002. Informal co-ordination of MRLs established in Council Directives 76/895/EEC, 86/362/EEC, 86/363/EEC, 90/642/EEC

European Commission 2003 ${ }^{a}$. Commission Directive 2003/13/EC, amending Directive 96/5/EC on processed cereal-based baby foods for infants and young children. Official Journal of the European Union L 41, 33-35

European Commission 2003 ${ }^{\mathrm{b}}$. Commission Directive 2003/14/EC, amending Directive 91/321/EEC on infant formulae and follow-on formulae. Official Journal of the European Union L 41, 37-38

Hajslova J. 2000. Pesticides. In: Moffat C.F., Whittle K.J., editors. Environmental Contaminants in Food. Sheffield, CRC Press, 217-272

Hamilton D.J, Holland P.T., Ohlin B., Murray, W.J., Ambrus A., Baptista G.C., Kovacicova J. 1997. Optimum use of available residue data in the estimation of dietary intake of pesticides. Pure and Applied Chemistry 69, 1373-1410

Holland P.T., Hamilton D., Ohlin B., Skidmore M.W. 1994. Effects of storage and processing on pesticide residues in plant products. Pure and Applied Chemistry 66, 335-356

Joint Meeting on Pesticide Residues 1988. Pesticide Residues in Food. FAO Plant Production and Protection Paper, 93/2, Rome

Joint Meeting on Pesticide Residues 1989. Pesticide Residues in Food. FAO Plant Production and Protection Paper 99, Rome 
Joint Meeting on Pesticide Residues 1991. Pesticide Residues in Food. FAO Plant Production and Protection Paper 113/1, Rome

Joint Meeting on Pesticide Residues 1992. Pesticide Residues in Food. FAO Plant Production and Protection Paper 116, Rome

Matsumura F. 2004. Contemporary Issues in Pesticide Risk Assessment. Proceedings of the $15^{\text {th }}$ International Plant Protection Congress. p. 236

Murray D., Snelson J.T. 1978. Fenitrothion and bioresmethrin residues in milled products from a commercial flour mill. Report to Department of Primary Industry, Canberra, Australia

National Research Council 1993. Pesticides in the diets of infants and children. Washington DC: National Academy Press

Pesticide residues monitoring in foodstuffs of vegetable origin - Portugal 1999. Report concerning Directives 90/642/EEC, 86/362/EEC and Commission Recommendation 97/822/CE

SANCO/10476/2003. Quality Control Procedures for Pesticide Residues Analysis

Snelson J.T. 1979. The effect of processing on fenitrothion residues on raw bran. Report to Department of Primary Industry, Canberra, October 1979

Snelson J.T. 1987. Grain Protectants. Australian Centre for International Research, Canberra

Tomlin C.D.S., editor. 2000. The Pesticide Manual, Twelfth Edition, British Crop Protection Council

World Health Organisation 1997. Guidelines for predicting dietary intake of pesticide residues. Document WHO/FSF/FOS/97.7, 2nd rev. ed., Geneva 